\title{
The influence of HIV infection on the age dependence of squamous cell carcinoma of the skin in South Africa
}

\author{
B L Diffey, ${ }^{1}$ BSc, AKC, PhD, DSc; M Norval, ${ }^{2}$ BSc, PhD, DSc; P N Albers, ${ }^{3}$ BSocSci, MSc; C Y Wright, ${ }^{3,4}$ BSocSci, MSocSci, PhD \\ ${ }^{1}$ Dermatological Sciences, Institute of Cellular Medicine, Newcastle University, Newcastle upon Tyne, UK \\ ${ }^{2}$ Biomedical Sciences, University of Edinburgh Medical School, UK \\ ${ }^{3}$ Environment and Health Research Unit, South African Medical Research Council, Pretoria, South Africa \\ ${ }^{4}$ Department of Geography, Geoinformatics and Meteorology, Faculty of Natural and Agricultural Sciences, University of Pretoria, South Africa
}

Corresponding author: B L Diffey (brian.diffey@ncl.ac.uk)

\begin{abstract}
Background. Cancer incidence typically increases with age, but it is not known whether ethnic characteristics influence the age dependence of squamous cell carcinoma of the skin (SCC).

Objectives. (i) To determine the age dependence of SCC in the black African, coloured and white population groups of South Africa (SA) and (ii) to show whether any differences in the rate of change of age dependence could be influenced by diversity in behaviour and lifestyle, especially with regard to the prevalence of HIV infection, rather than by a fundamental variation in cancer biology between the populations. Methods. Linear regression analysis was applied to the logarithm of the age-specific incidence rates for SCC v. the logarithm of age between 35 and 74 years. The slopes of the regression (age exponent) were compared for each subset of gender, population group and year of diagnosis (between 2000 and 2010).

Results. The most notable feature was the low value of the age exponent in both male and female black African compared with the white and coloured populations. This finding could be explained in part by the difference in the prevalence of HIV infection in the black African population group compared with the white and coloured population groups.

Conclusions. The prevalence of HIV infection in black Africans in SA tends to decrease the apparent age component in SCC compared with the white and coloured population groups. Other factors relating to lifestyle and behaviour that differ between the population groups are also likely to influence the age component in SCC.
\end{abstract}

S Afr Med J 2017;107(2):127-129. DOI:10.7196/SAMJ.2017.v107i2.10837

The incidence of most common cancers increases with age in both males and females worldwide. An explanation for this observation is provided by the multistage model for carcinogenesis in which the tumour arises as a result of the multiple genetic changes acquired during ageing. ${ }^{[1-3]}$ Additionally, the efficacy of the immune system diminishes with ageing, which may contribute to the age-related increase in cancer incidence. In the present analysis, the age dependence of squamous cell carcinoma of the skin (SCC) in the black African, coloured and white population groups of South Africa (SA) was examined.

The evidence that exposure to sunlight is the predominant cause of SCC in humans is very convincing. These cancers occur almost exclusively on sun-exposed skin such as the face, neck and arms, and the incidence is clearly correlated with geographical latitude, being higher in the more sunny areas of the world. ${ }^{[4]}$ Epidemiological studies suggest that sun exposure in the 10 years prior to diagnosis may be important in accounting for individual risk of SCC. ${ }^{[5]}$

Our objective in this study was to distinguish whether any differences found in the rate of change of age dependence between the population groups were due to behaviour and lifestyle factors. One lifestyle factor of particular interest in the context of SA is the high incidence of HIV infection.

In 2012, it was estimated ${ }^{[6]}$ that $12.2 \%$ of the SA population (6.4 million persons) were HIV-positive, with the prevalence being highest among females aged 30 - 34 years and among males aged 35 - 39 years. There are significant ethnic differences in HIV prevalence: ${ }^{[6]} 15 \%$ in the black African population compared with $3.1 \%$ in the coloured and $0.3 \%$ in the white populations. It has been observed $^{[7]}$ that there is an increase in SCC in HIV-infected black Africans (odds ratio (OR) 2.6; 95\% confidence interval (CI) 1.4 4.9). Of those infected with HIV in SA, more than $50 \%$ are currently treated with antiretroviral therapy (ART), from a base of $7 \%$ in $2007 .{ }^{[8]}$ A recent review of observational studies monitoring the risk of cancer concluded that the incidence of non-AIDS-defining cancers rose after starting ART, possibly owing to increased life expectancy or to the genomic instability caused by the drugs. ${ }^{[9]}$ Two studies indicate that HIV-positive white individuals have a higher incidence of SCC than HIV-negative individuals. ${ }^{[10,11]} \mathrm{HIV}$ is therefore likely to have an impact on the age dependence of SCC in $\mathrm{SA}$, regardless of population group.

\section{Methods}

Age-specific incidence rates in 5-year age bands for SCC in SA during the period 2000 - 2010 were obtained from National Cancer Registry (NCR). ${ }^{[12]}$ The HIV status of individuals was not recorded by the NCR, which is a pathology-based registry that receives reports on patients diagnosed with cancer from all public and private sector histology, cytology and haematology laboratories in SA. Data were obtained separately for the black African, coloured and white population groups and for males and females. We excluded skin cancer in Indians/Asians as this group comprises only $2.5 \%$ of the SA population with very low absolute numbers of SCC diagnosed each year, leading to unreliable estimates of age-specific incidence. 
The most common cancers arise in epithelial tissue late in life, increasing in incidence with roughly the fifth or sixth power of age. ${ }^{[1]}$ This is expressed mathematically as: ${ }^{[2]}$

$$
\mathrm{I}(\mathrm{t}) \alpha \mathrm{t}^{a}
$$

where $I(t)$ is the incidence at age $t$ and $\alpha$ is a constant.

Consequently, for each subset (population group, gender, year of diagnosis of SCC), linear regression analysis was applied to the logarithm of incidence rates using the logarithm of mid-age in each age band as the regressor variable for incidence rates between the ages of 25 and 74 years. The slope of the regression is equal to the age exponent $\alpha$. These age boundaries were chosen because the incidence rate of SCC is low under 25 years and the rates over 74 years tend to be unreliable as the numbers of absolute cases are few, especially in the black African population. Also, it is recognised that the agespecific incidence increasingly deviates in later life below the line defined by the log-log relationship, one factor being that all the susceptible individuals in a population have already developed the tumour. ${ }^{[3]}$ Other possible biological mechanisms for this observation include increasing apoptosis and cell senescence with age. ${ }^{[13]}$

\section{Results}

As an illustration of the number of SCCs diagnosed in SA in one year, the most recent data available ${ }^{[12]}$ are shown in Table 1. Fig. 1 provides an example showing incidence v. age for 2010 for SCC in males and females and by population group. A summary of

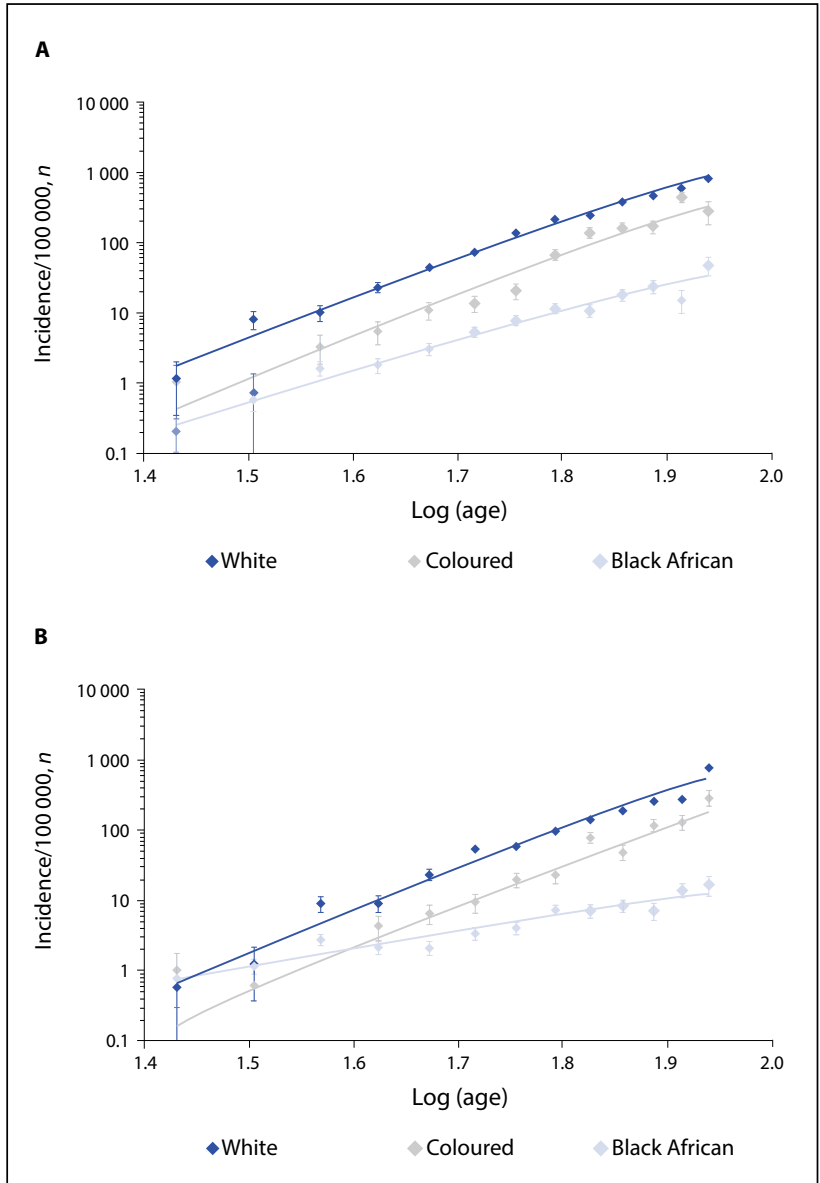

Fig. 1. Incidence ( \pm 1 standard deviation) of squamous cell carcinoma of the skin in 2010 in SA as a function of age for white, coloured and black African males (A) and females $(B)$. the age exponents obtained from the regression analysis is given in Table 2. Also shown in Table 2, for comparison, are the age exponents calculated using data from England for the year 2011 (personal communication, National Cancer Intelligence Network, Public Health England), south-east Netherlands for the period $1978-1988^{[14]}$ and Scotland for $1989-2013 .{ }^{[15]}$ These data relate almost entirely to people with white skin, some of whom share close genetic traits with the white population of SA. The most notable feature is the low value of the age exponent in both male and female black Africans compared with the white and coloured populations and the European groups. While the solar environment of northern Europe is less intense than that of SA, this factor is likely to influence the age exponents to a much smaller degree than phenotype and genotype characteristics.

To estimate how HIV infection in black Africans might influence the age exponent for SCC, the expected age-specific rate in the absence of HIV $\left(A S R_{\text {exp }}\right)$ for each age band and gender was calculated as:

$$
\mathrm{ASR}_{\text {exp }}=\mathrm{ASR}_{\mathrm{obs}} /\{(1-\mathrm{P})+\mathrm{OR} \times \mathrm{P}\}
$$

where $A S R_{\text {obs }}$ is the observed age-specific rate for the year 2010 (the latest available data), $P$ is the prevalence of HIV infection in 2012 for the given gender and age band ${ }^{[6]}$, and $O R$ is the odds ratio for SCC in HIV-infected black Africans. ${ }^{[7]}$ Logarithmic regression analysis performed as described above resulted in an increase in the age exponent for SCC from 4.3 to 4.7 (95\% CI 4.4 - 5.0) in male black Africans, and from 2.3 to 2.8 (95\% CI 2.5 - 3.3) in female black Africans. Although these revised age exponents are closer to those for the coloured and white population groups, it would appear that HIV infection only partially accounts for the low age exponent for SCC found in black Africans (Table 2).

\section{Discussion}

This analysis has compared the age exponents for SCC in three population groups in SA. Although the NCR was established as a pathology-based cancer reporting system, the private health labora-

Table 1. SCCs of the skin diagnosed in the four population groups in SA in 2010

\begin{tabular}{lll}
\hline & Males, $n$ & Females, $n$ \\
\hline Black African & 319 & 323 \\
Coloured & 254 & 184 \\
White & 1813 & 1228 \\
Asian/Indian & 25 & 14
\end{tabular}

Table 2. Age exponents ( \pm 1 standard deviation) for SCC of the skin in the black African, coloured and white population groups in SA, and in England, The Netherlands and Scotland

\begin{tabular}{lll}
\hline Group & Males & Females \\
\hline SA black & $3.9(0.35)$ & $2.4(0.34)$ \\
SA coloured & $6.4(0.56)$ & $5.5(0.79)$ \\
SA white & $5.2(0.32)$ & $5.1(0.57)$ \\
England & $6.8(0.77)$ & $6.2(0.69)$ \\
Netherlands & $6.6(2.43)$ & $4.1(1.17)$ \\
Scotland & $6.9(0.64)$ & $5.4(0.70)$
\end{tabular}


tories withheld cancer reports from 2005 to 2007 owing to concerns regarding voluntary sharing of patient data. While private healthcare reporting to the NCR decreased by $28 \%$ from 2005 to 2007 , it is estimated $^{[16]}$ that this represented a minimal impact on overall cancer reporting (net decrease of $<4 \%$ ). The mismatch between the observed and estimated numbers of cancers would impact mainly on affluent South Africans in all population groups, who are most likely to use private health laboratories. Less affluent people tend to receive care in the public healthcare system. Mandatory reporting was legislated in 2011, and data for 2011 onwards are not yet available from the NCR. Whether changes in reporting led to an increase in incidence after 2011 therefore cannot be determined.

It is notable that the age exponent for SCC in blacks was lower than that in coloureds and whites. It is possible that this may reflect the different risk factors for SCC due to solar ultraviolet (UV) radiation exposure in these ethnic types. In people with deeply pigmented skin, SCCs occur about eight times more frequently on non-exposed body sites than in white people, frequently developing on body sites where there is chronic scarring and inflammation, such as on the lower limbs, ${ }^{[17]}$ where sun exposure is unlikely to present the same risk factor for carcinogenesis as on the head and neck.

We have shown that the prevalence of HIV infection in black Africans would tend to decrease the apparent age exponent in SCC. In our analysis, we assumed that the OR was independent of age and calendar year. Prevalence data for the year 2012 but incidence data for 2010 were used, as these were the most recent results available. The first deaths from AIDS in SA were reported in 1985, and HIV prevalence has remained relatively constant since 2002. We did not know the duration of HIV infection in each individual, and whether this might have impacted on the expected age standardised rates given by equation (2).

\section{Conclusions}

We have demonstrated that extrinsic factors, in this case HIV status and SCC, can modify the calculated age exponent of cancer, and so differences in age exponents between diverse population groups do not necessarily infer differences in the number of discrete stages by which a normal cell is transformed into a malignant one.

Acknowledgements. CYW receives funding support from the National Research Foundation of South Africa and the South African Medical Research Council.

\footnotetext{
1. Armitage P, Doll R. The age distribution of cancer and a multi-stage theory of carcinogenesis. Br J Cancer 1954;8(1):1-12.

2. Doll R. The age distribution of cancer: Implications for models of carcinogenesis. J R Stat Soc Ser A 1971;134(2):133-166. http://dx.doi.org/10.2307/2343871

3. Cook PJ, Doll R, Fellingham SA. A mathematical model for the age distribution of cancer in man. Int J Cancer 1969;4(1):93-112. http://dx.doi.org/10.1002/ijc.2910040113

4. Kricker A, Armstrong BK, English DR. Sun exposure and non-melanocytic skin cancer. Cancer Causes Control 1994;5(4):367-392.
Cricker A, Armstrong BK, Engtis

Gallagher RP, Hill GB, Bajdik CD, et al. Sunlight exposure, pigmentation factors, and risk of Gallagher RP, Hill GB, Bajdik CD, et al. Sunlight exposure, pigmentation factors, and r
nonmelanocytic skin cancer: II. Squamous cell carcinoma. Arch Dermatol 1995;131(2):164-169.

nonmelanocytic skin cancer: II. Squamous cell carcinoma. Arch Dermatol 1995;131(2):164-169.
6. Shisana O, Simbayi T, Zuma K, et al. South African National HIV Prevalence, Incidence and Behaviour Survey 2012. Cape Town: HSRC Press, 2014. http://www.hsrc.ac.za/en/research-data/view/687 (accessed 23 March 2016)

7. Stein L, Urban MI, O'Connell D, et al. The spectrum of human immunodeficiency virus-associated cancers in a South African black population: Results from a case-control study, 1995-2004. Int J Cancer 2008;122(10):2260-2265. http://dx.doi.org/10.1002/ijc.23391

8. Bekker LG, Venter F, Cohen K, et al. Provision of antiretroviral therapy in South Africa: The nuts and bolts. Antivir Ther 2014;19(Suppl 3):105-116. http://dx.doi.org/10.3851/IMP2905

9. Cobucci RN, Lima PH, de Souza PC, et al. Assessing the impact of HAART on the incidence of defining and non-defining AIDS cancers among patients with HIV/AIDS: A systematic review. I Infect Public Health 2015;8(1):1-10. http://dx.doi.org/0.1016/j.jiph.2014.08.003

10. Silverberg MJ, Leyden W, Warton EM, Quesenberry CP, Engels EA, Asgari MM. HIV infection status, immunodeficiency, and the incidence of nonmelanoma skin cancer. J Natl Cancer Inst 2013;105(5):350-360. http://dx.doi.org/10.1093/jnci/djs529

11. Barnes E, Saxon C, Ahmad S. Cancer prevalence in a metropolitan HIV clinic. J Int AIDS Soc 2014;17(Suppl 3):19651. http://dx.doi.org/10.7448/IAS.17.4.19651

12. National Cancer Registry. http://www.nioh.ac.za/?page=cancer_statistics\&id=163 (accessed 23 March 2016

13. Pompei F, Wilson R. Age distribution of cancer: The incidence turnover at old age. Hum Ecol Risk Assess 2001;7(6):1619-1650.

14. Coebergh JW, Neumann HA, Vrints LW, van der Heijden L, Meijer WJ, Verhagen-Teulings MT. Trend in the incidence of non-melanoma skin cancer in the SE Netherlands 1975-1988: A registry-base study. Br J Dermatol 1991;125(4):353-359.

5. Information Services Division, NHS National Services, Scotland. http://www.isdscotland.org/HealthTopics/Cancer/Cancer-Statistics/Skin/ (accessed 23 March 2016).

16. Singh E, Underwood JM, Nattey C, Babb C, Sengayi M, Kellett P. South African National Cancer Registry: Effect of withheld data from private health systems on cancer incidence estimates. S Afr Med J 2015;105(2):107-109. http://dx.doi.org/10.7196/SAMJ.8858

17. Gloster KM, Neal K. Skin cancer in skin of color. J Am Acad Dermatol 2006;55(5):741-760. http:// dx.doi.org/10.1016/.j.jaad.2005.08.063
}

Accepted 20 October 2016. 